\title{
Obituary
}

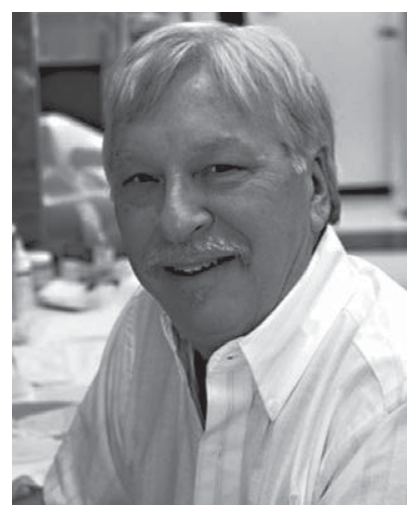

\section{LARRY SPARKS: INNOVATOR AND ICONOCLAST}

The Alzheimer community lost Larry Sparks, one of its greatest innovators, on 14 May 2013. Larry was never shy about bringing new insights to discover and inform, whether cholinergic function, cholesterol, or copper. Through his insightful work on the link between heart and Alzheimer's diseases, Larry was the first to demonstrate an association between cholesterol and amyloid plaque deposition. He further showed that this association is mediated by copper metabolism, and was the first to test the efficacy of a cholesterollowering agent in the treatment of Alzheimer's disease. He was the author of over 100 research articles, many published in the most prestigious scientific journals, and his seminal contributions to the relationship between heart and Alzheimer's diseases were described in numerous national and scientific news outlets, including a cover article in Newsweek. His work was revolutionary in linking heart health to brain health-a new mainstream idea that is a direct result of Larry's perseverance and innovation.
Larry, an indefatigable researcher, also left his mark in forensic neuroscience. During his Kentucky years, he proposed novel evidence-based data on postmortem chemistry and time-of-death estimation. More importantly, he tirelessly pursued research in the cause of death in Sudden Infant Death Syndrome (SIDS), which, in tandem with studies on the neuropathology of aging, led him to be the first to propose that SIDS is a neurodegenerative disorder. Deeply empathetic with families coping with the unanticipated death of a young infant, he spoke often to such parents, and assured them in his seminal paper: "There is nothing you could have done."

After earning his $\mathrm{PhD}$ in Biochemistry at the Medical University of South Carolina, Larry became a faculty member at the University of Kentucky in the Departments of Pathology, Pharmacology and Experimental Therapeutics, and a Chief Biochemical Consultant with the Kentucky Medical Examiner's Program. He joined Sun Health Research Institute in 1997.

Larry loved his research, he treasured the idea of taking out-of-the-box approaches to helping address important problems of public health in the most impactful way, and he cherished the time he spent with his wife Lisa fishing at their vacation home in the Florida Keys. His contribution will continue to grow in our field.

Marwan N. Sabbagh George Perry

John C. Hunsaker III Bernard Schreurs 